\title{
A CARTOGRAFIA COMO MÉTODO: \\ POTENNCIAS E DEVIRES \\ PARA AS PRÁTICAS \\ EM ANÁLISE \\ DO DISCURSO
}

\section{LA CARTOGRAFÍA COMO MÉTODO: POTENCIAS Y DEVENIRES PARA LAS PRÁCTICAS EN EL ANÁLISIS DEL DISCURSO}

\author{
CARTOGRAPHY AS A METHOD: FORCES AND BECOMINGS FOR DISCOURSE ANALYSIS \\ PRACTICES
}

Juliana Silva Rettich*

Universidade Estadual do Rio de Janeiro

\begin{abstract}
RESUMO: Este ensaio tem como objetivo narrar o processo feito ao longo da dissertação de mestrado no Programa de PósGraduação em Letras, na área de Estudos de Língua, com a abordagem da Análise do Discurso francesa, cujos pilares foram Dominique Maingueneau e Michel Foucault. No entanto, aqui, será apresentado o método da cartografia, a partir de uma perspectiva deleuziana, tendo como principal suporte teórico o livro Pistas do Método Cartográfico: pesquisa intervenção e produção de subjetividade. O resultado é a possiblidade de entrelaçar narrativamente teoria e prática, apresentando a potência desse método em outras áreas das ciências que não só a psicologia. A pesquisa de mestrado se deu a partir da análise do PL 867/2015, fruto do movimento Escola Sem Partido, com a construção de uma rede discursiva, composta por esse projeto de lei, seus apensados, além do PL 14111/2015, que tipifica como crime o chamado assédio ideológico em sala.
\end{abstract}

PALAVRAS-CHAVE: Escola Sem Partido. Análise do Discurso. Cartografia. Método.

RESUMEN: El objetivo de este ensayo es describir el proceso realizado durante la tesis de maestría en el Programa de Postgrado en Letras, en el área de Estudios del Lenguaje, con el enfoque del Análisis del Discurso Francés, cuyos pilares fueron Dominique Maingueneau y Michel Foucault. Sin embargo, aquí se presentará el método de cartografía, basado en una perspectiva deleuziana, teniendo como principal soporte teórico el libro Pistas del Método Cartográfico: intervención-investigación y producción de subjetividad. El resultado es la posibilidad de entrelazar narrativamente teoría y práctica, presentando la potencia de este método en

*Mestre e doutoranda do Programa de Pós-Graduação de Letras da Universidade do Estado do Rio de Janeiro, na área de Estudos de Língua, em Linguística. Atualmente é professora substituta do Departamento de Linguística do Instituto de LetrasdaUERJ.E-mail:jsrettich@gmail.com. 
otras áreas de la ciencia que no son solo la psicología. La investigación de maestría se basó en el análisis del PL 867/2015, resultado del movimiento Escuela sin Partido, con la construcción de una red discursiva compuesta por este proyecto de ley y sus anexos, además del PL 14111/2015, que tipifica como delito el llamado asedio ideológico en el aula.

PALABRAS CLAVE: Escuela sin Partido. Análisis del Discurso. Cartografía. Método.

ABSTRACT: This essay aims at describing the process carried out during the master's thesis in the Postgraduate Program in Languages, in the area of Language Studies, with the French Discourse Analysis approach, whose pillars are Dominique Maingueneau and Michel Foucault. However, here, the method of cartography will be presented based on a Deleuzian perspective, having as main theoretical support the book Pistas do Método da Cartografia: pesquisa-intervenção e produção de subjetividade. The result is the possibility of narratively intertwining theory and practice, presenting the power of this method in areas of science beyond psychology. The master's research was based on the law proposal PL 867/2015 analysis, a result of the movement Escola Sem Partido [Nonpartisan School], through the construction of a discursive network, composed of related law proposals, in addition to PL 14111/2015, which typifies the so-called crime of "ideological harassment" in the classroom.

KEYWORDS: Nonpartisan School. Discourse Analysis. Cartography. Method.

\section{INTRODUÇÃO}

O começo de um texto talvez não seja exatamente o seu começo. E isso a cartografia ajuda a compreender. O primeiro capítulo de uma dissertação, por exemplo, pode não ser o primeiro a ter sido escrito e até pensado. Pode, inclusive, nem ter feito parte dos planos iniciais de pesquisa, das hipóteses levantadas diante de um tema escolhido. Talvez, diante desse formato de pensar pesquisa e materializá-la no texto, o importante é ser honesta com os possíveis interlocutores, indicando o caminho percorrido. É sobre caminho mesmo. Compreendi que o importante é ter um ponto de partida - não fixo, rígido, sem possibilidades de deslocamentos - e minimamente uma razão para iniciar, o ponto de chegada é indicado ao longo desse caminho da pesquisa, permitindo-se, como pesquisadora, ser implicada pelo objeto e implicá-lo igualmente. O desafio, então, não é definir antecipadamente o resultado da pesquisa; é permitir-se caminhar com ela, numa dança cartográfica, para viver as surpresas que um objeto de estudo pode nos oferecer se não nos colocarmos imponentes diante do tema pesquisado. É essa possibilidade que nos traz o método da cartografia como um caminho produtivo de pesquisa em linguística, na área da Análise do Discurso, uma vez que compor as redes discursivas materializadas por diversos textos está longe de ser uma coleta de dados dentro de uma linearidade de resultados. Textos produzidos, por vezes em suportes diferentes, por vezes com focos diferentes, podem materializar os discursos que estamos nos propondo a analisar. Desse modo, cartografar, mapear e analisar os processos desse ato cartográfico tem sido hoje o caminho que mais utilizo para produzir minhas pesquisas em Análise do Discurso.

Este trabalho tem como objetivo narrar, ou seja, tornar dizível o caminho que percorri na minha dissertação de mestrado e que, nem sempre, era tão claro. Com o título Do visor na porta das salas de aula à mordaça nos professores: uma análise discursiva das redes conservadoras do Escola Sem Partido - Projeto de Lei867/2015, cheguei à banca em março de 2018 com mais de cem páginas que ainda não são tão fáceis de explicar. Meses depois, em um evento de linguística, fui questionada sobre a cartografia, método que utilizei no trabalho, e tive que esperar alguns minutos para responder. Percebi, então, que talvez fosse necessário retomar o caminho que fiz durante dois anos e tentar escrevê-lo. Para isso, conto com as minhas lembranças, mais até do que com o que escrevi para o mestrado. E, propositalmente, contarei com as minhas lembranças porque acredito que elas sejam também um dispositivo de produção de subjetividade que ressignifica a minha dissertação de mestrado todas as vezes em que preciso retornar a ela.

Antes, preciso também dizer de onde parto como sujeito em constante processo de subjetivação. Sou jornalista formada pela Universidade Federal do Rio de Janeiro; anos depois de formada, decidi dar aula - trabalhei no Pré-Vestibular Social do Estado do Rio de Janeiro (PVS-CEDERJ), ministrando aulas de redação - e fazer um novo vestibular. Sou agora também formada em Letras, pela Universidade do Estado do Rio de Janeiro, onde comecei a pesquisa, ainda na graduação, em Análise do Discurso de Base Enunciativa, com o professor Décio Rocha, que também foi meu orientador de mestrado, realizado na mesma instituição. Dou aula 
de redação há dez anos, comecei, como disse no PVS, e há sete anos trabalho em escolas privadas. Estou iniciando o segundo ano do doutorado, também na UERJ, também na AD de Base Enunciativa, e agora com a professora Poliana Coeli como orientadora.

Desse modo, como a cartografia é um processo movente, contínuo, não acabado, este ensaio está dividido em apenas três partes, sendo elas: Introdução, Cartografia como dispositivo e potência e Considerações finais. E, além do objetivo já mencionado de narrar, tornar dizível o que temos feito com o método cartográfico, acrescenta-se a isso mais um objetivo: apresentar a cartografia como uma outra opção de método de pesquisa científica nas práticas acadêmicas.

\section{A CARTOGRAFIA COMO DISPOSITIVO E POTÊNCIA}

Já de início preciso marcar por que escrever este caminho, uma vez que não o terminarei agora, tampouco sei quantas páginas-tempo terei pela frente. Após a defesa, ainda sem saber muito bem definir precisamente o resultado do meu trabalho sobre a análise do Projeto de Lei 867/15, do Programa Escola Sem Partido, tive alguns momentos nos quais me foi colocada a difícil tarefa de explicar como a cartografia apareceu no meu texto, como ela foi a ferramenta para a pesquisa, como ela foi também um dispositivo de produção de subjetividade sobre mim mesma enquanto desenvolvia minha pesquisa. Para responder, tentava mapear mentalmente esse caminho, o que decidi, então, registrar aqui.

Antes, falo um pouco sobre o método da cartografia. Barros e Kastrup (2015, p. 53) ${ }^{1}$ afirmam que "[...] a pesquisa cartográfica consiste no acompanhamento de processos, e não na representação de objetos”. Enquanto avanço nesse desejo de escrever sobre o processo que acompanhei no mestrado, vejo-me na obrigação de relatar também o processo que acompanho agora nesta escrita de um caminho percorrido, compreendendo assim que aqui é mais um novo caminho que se percorre.

Desse modo, preciso falar das forças que me atravessam e me implicam como pesquisadora, aluna do doutorado, professora de Ensino Médio, com muitas ideias na cabeça e pouco tempo para escrevê-las; acredito ser importante dizer que este novo processo de escrita vem se dando de forma picotada, bem como a releitura teórica para ele. Esse vai e volta na leitura e na escrita parece constituir-se como novos dispositivos de produção de subjetividade que me proporcionam formas diferentes de olhar para esse objeto estudado e para este texto que me propus a fazer, bem como para a minha vida, claro, compreendendo que estou sendo implicada por todas essas produções. É a possibilidade do devir por meio desses vetores que nos atravessam o tempo todo, produzindo novos encontros e deslocamentos. Nesse novo caminho, recorro à minha memória compreendendo-a hoje como também um dispositivo de produção de subjetividade, o qual me sinto na obrigação de trazer aqui explicitamente a partir da noção de que não vou, com a ajuda da memória, representar um tempo, uma pesquisadora e um objeto estudado entre 2016 e 2018, mas estou aqui construindo, com esse mesmo dispositivo memória, um outro tempo, uma outra pesquisadora e um outro objeto, já que não represento o que foram, lá nos dois anos de mestrado, esses três pontos neste ensaio, e sim acompanho processos de como tempo, pesquisadora e objeto vão se dando cada vez que novos enunciados são produzidos sobre eles - e aqui a pesquisadora sou eu mesma.

Antes de avançar, cabe pontuar com qual conceito de dispositivo de produção de subjetividade tenho trabalhado, não só aqui, como também em outros projetos. Somos sujeitos em constante processo de produção de subjetividade. Ou seja, tal subjetividade é constante e processual, não é o ponto de chegada, mas tem a ver com os acontecimentos que nos formam a partir dos dispositivos com os quais temos contato. Se para Michel Foucault ${ }^{2}$ esses dispositivos têm a ver com as prisões, os manicômios, o panóptico, as escolas, as confissões, as fábricas, as disciplinas, as medidas jurídicas etc., por exemplo, tenho preferido a ampliação de Giorgio Agamben em relação ao conceito, já que, para ele, o que está a nossa volta e com o que nos relacionamos pode ser visto como dispositivo de produção de subjetividade. O autor diz que dispositivos também podem ser aquilo que não tem uma relação tão evidente com o poder, como "[...] a caneta, a escritura, a literatura, a filosofia, a agricultura, o cigarro, a navegação, os computadores,

\footnotetext{
${ }^{1}$ Pista 3 do livro Pistas do método Cartográfico (pesquisa-intervenção e produção de subjetividade). O livro é dividido em oito pistas em que consistiria o método da cartografia, com o qual trabalhei ao longo da pesquisa do mestrado e trabalho agora na escrita deste trabalho.

${ }^{2}$ Para isso, ver O que é um dispositivo, de Giorgio Agamben.
} 
os telefones celulares e - porque não - a linguagem mesma, que é talvez o mais antigo dos dispositivos [...]” (AGAMBEN, 2005, p. 13). Nesse sentido, essa concepção de dispositivo ajuda a compreender que há uma série deles, para além do que Foucault lista, que nos atravessam ou nos encontram, formando constantemente nossas subjetividades. Enquanto fazia minha pesquisa de mestrado, o objeto que escolhi, os discursos sobre o Escola Sem Partido, constituía-se como dispositivo, promovendo processo de subjetivação em mim. Ao recorrer à minha memória, para a construção deste trabalho, ela também se constitui como mais um dispositivo que produzirá algum encontro possibilitando novos devires. Além disso, ao escrever sobre esses processos, produzo novos enunciados que também se constituem como dispositivos de produção de subjetividade para quem for ler. Como afirmo na minha dissertação de mestrado ,retomando a fala do professor Bruno Deusdará, em um dos nossos encontros de pesquisa, não existe dispositivo que não tenha uma dimensão discursiva, e, quando falo de discurso, falo também de linguagem, uma das dimensões do dispositivo.

No acompanhamento dos processos dessa minha memória, tenho visitado e revisitado afetos que estiveram presentes nos dois anos de leitura e análise do Projeto de Lei Programa Escola Sem Partido. Meu desejo aqui é poder narrar esses afetos, torná-los dizíveis como evidentes potências de deslocamentos. Em "Cartografia sentimental - Transformações Contemporâneas do Desejo”, Rolnik (2006, p. 23) diz que: "Sendo tarefa do cartógrafo dar língua para os afetos que pedem passagem, dele se espera basicamente que esteja mergulhado nas intensidades de seu tempo e que, atento às linguagens que encontra, devore as que lhe parecerem elementos possíveis para a composição das cartografias que se fazem necessárias. O cartógrafo é, antes de tudo, um antropófago.”.

Hoje, então, escrevo sobre a feitura da dissertação, buscando narrar os processos que acompanhei na época a partir da visão cartográfica, lembrando que a memória é uma força que atua nesse objeto que agora retomo, dentre outras tantas forças que estiveram e estão sobre ele, na metaestabilidade que possibilita devires muitos acerca disso que vim tecendo. Falo de forças sobre o objeto retomando a Pista 5 do livro "Pistas do Método Cartográfico". O método tradicional de pesquisa considera o objeto a ser pesquisado já existente e apenas como algo a ser revelado por meio dos estudos. Nesse caminho pelo qual nos propomos ir como grupo de pesquisa, compreendemos que existem forças que produzem os objetos e por isso também nos propomos narrar esses processos de produção. Escóssia e Tedesco (2015, p. 92) dizem:

No contexto do livro, desenvolveremos neste texto a pista que indica a cartografia como prática de construção de um plano coletivo de forças. Plano geralmente desconsiderado pelas perspectivas tradicionais de conhecimento, ele revela a gênese constante das formas empíricas, ou seja, o processo de produção dos objetos do mundo, entre eles, os efeitos de subjetivação. Ao lado dos contornos estáveis do que denominamos formas, objetos ou sujeitos, coexiste o plano das forças que os produzem.

Essa nova forma eu chamei de dissertação de mestrado sobre o Escola Sem Partido, com o título Do visor na porta das salas de aula à mordaça nos professores: uma análise discursiva das redes conservadoras do Escola Sem Partido - Projeto de Lei867/2015. E a cartografia como esse plano de forças torna-se a potência para múltiplos devires, tanto para o objeto de estudo quanto para o pesquisador, uma vez que nos leva à compreensão de que o que pesquiso é um dispositivo de produção subjetividade, assim como também eu o sou sobre o objeto estudado, colocando-me sensível e atenta aos processos ao longo do tempo de pesquisa. O que escrevi na dissertação não estava dado, não estava lá e eu apenas revelei, foi produto de muitas implicações, muitas forças, até chegar à escrita final, a qual não é o final do percurso, já que ela traz possibilidades outras de produção de subjetividade e, como plano de forças, de interferência sob outras formas ao ser lida como dissertação.

Parece importante destacar que ao produzir esse enunciado dissertação, do modo como decidi produzir, assumindo o caminho cartográfico, no qual narro necessariamente os processos de pesquisa e de feitura do trabalho, interfiro no mundo por meio da linguagem. Assim sendo, aqui também vou dando língua aos afetos que não posso dizer que são exatamente os que me deslocaram lá na pesquisa ou se são os que me deslocam agora, porque narrar é construir novas formas. Acho que já está claro que aqui reconstruo e produzo um novo objeto dissertação de mestrado a partir do dispositivo memória e, ao narrar, o faço a partir do dispositivo enunciativo.

Pensando nisso, de a memória ser um dispositivo, tem sido um novo caminho revisitar a trajetória da pesquisa que tem me levado a surpresas por tentar me permitir uma leitura despretensiosa do livro "Pista do Método Cartográfico", em função do grupo de pesquisa, uma vez que, embora no doutorado, encontro-me num estágio inicial, permitindo-me, por conta dos três anos que ainda 
tenho, experimentar novos encontros ao reler textos que já tinha lido. Hoje vejo mais fortemente que cartografar tem a ver com se permitir às surpresas que os textos nos trazem, sem levantar hipóteses (expectativas) sobre eles e sem ir por um caminho hermenêutico para buscar encontrar as respostas a essas hipóteses, a fim de corresponder às expectativas e sentir o prazer "científico" de ter razão ao vê-las se concretizar no empirismo. Sobre as surpresas, temos na Pista 6 o seguinte:

[...] o cartógrafo acompanha um processo que, se ele guia, faz tal qual como o guia de cegos que não determina para onde o cego vai, mas segue também às cegas, tateante, acompanhando um processo que ele também não conhece de antemão. O cartógrafo não toma o eu como objeto, mas sim os processos de emergência do si como desestabilização dos pontos de vista que colapsam a experiência no ("interior") eu. (EIRADO; PASSOS, 2015, p. 123)

Antes de avançar, volto um pouco e esclareço como esse método passou a fazer parte dos meus estudos. Desde 2012, participo do grupo de trabalho liderado por três professores do Departamento de Linguística da UERJ, Bruno Deusdará, Décio Rocha e Poliana Coeli. Ao longo desses anos, apareceram as leituras do "Pistas do Método Cartográfico" e as discussões sobre como as pistas poderiam nos ajudar enquanto método de pesquisa na área de linguagem, já que comumente elas aparecem como uma metodologia para a psicologia.

A pergunta que hoje me faço, após a leitura da Pista 6, é: por que escolhi esse método como caminho para a minha pesquisa? Será que foi porque os professores disseram para seguir esse método? Ou será que ele atua de algum modo em mim a ponto de eu ver sua potência e seu sentido na área de estudo que escolhi? Nessa pista, os autores Passos e Eirado (2015) falam sobre um plano de ação ou um plano de pesquisa que tem a tríade transversalidade, implicação e dissolução do ponto de vista. Para responder à minha pergunta sobre a escolha do método, fiquei pensando se era possível falar de fora de um lugar em que estou implicada e tocada por essas leituras, que passaram a fazer sentido não só para a pesquisa, mas para a maneira como me coloco no mundo. Tentando olhar para a dissertação feita, a questão foi: como eu faria uma análise de discurso com outro método a partir da análise de enunciados cujos sujeitos não são empíricos e são atravessados por processos de subjetividade diversos, a partir dos quais muitas vozes se dão nesses enunciados analisados? E como eu conseguiria ter um olhar de fora, objetivo, cientificista, para responder a esse questionamento, se sou também uma pessoa em processos de subjetivação, atravessada por diversas forças, inclusive o Projeto de Lei Escola Sem Partido? Ou seja, há uma rede de forças que se comunicam (transversalidade) e que produzem subjetividades no objeto da pesquisa e no pesquisador, estando ambos implicados (implicação), e que culminam nos relatos que ganham nome de dissertação, sem a possibilidade de não estar diluído o meu ponto de vista, porque não só observo, mas sou afetada o tempo todo por aquilo que estudo e afeto o que estudo o tempo todo também, produzindo realidades com o que escrevo sobre esse objeto estudado. Isso tudo para dizer que ainda não tenho resposta que seja suficiente para acolher a reflexão acerca do método escolhido. Como costumo dizer, a cartografia parece cair como uma luva para essa análise do discurso que decidimos praticar.

Temos um método! Se método é uma das premissas para se fazer ciência, nós o temos. E nessa disputa de sentido do que é ou não ciência, se fazemos ciência, se fazemos análise do discurso ou interpretação de texto, vinham com muita frequência para mim essas questões, como vetores que chamavam à responsabilidade do que me propus a estudar e do que me propus a trazer como resultado na escrita da dissertação. Esse compromisso fazia com que eu andasse em muitos lugares levando parte do meu corpus na bolsa e relendo-o muitas vezes para ser afetada por possíveis entradas linguísticas que me serviriam à análise. Era o Projeto de Lei 867/15 ainda não tinha começado a ler os seus apensados (PL 7180/ 2014; PL 7181/ 2014; PL 1859/2015; PL 5487/2016; PL 6005/2016), além do PL 14111/2015, que tipifica como crime o chamado assédio ideológico em sala.

Já em contato com algumas leituras da cartografia, tinha noção de que eu não coletaria dados e descobriria resultados; aqui sabemos que construímos o corpus, bem como os resultados da pesquisa, porque estamos implicados - pesquisadora e objeto - e, ao escrever, nosso trabalho será mais um enunciado acerca daquele objeto, constituindo-se como mais um vetor de força sob essa forma (objeto de análise), produzindo-o novamente. Aqui sempre me lembro do que Veyne ${ }^{3}$ (2014), também citado em minha dissertação, escreve

${ }^{3}$ Como se escreve a história - Foucault revoluciona a história: essa parte do livro é dedicada a Michel Foucault, como uma resposta aos que diziam que o filósofo não fazia história, embora trabalhasse com evidências, como o autor vai discutir em seu livro. Para Veyne (2014), Foucault é um historiador porque não só trabalha com as evidências de documentos conhecidos, como tantos outros historiadores, mas também porque trabalha com os drapeados da história, com o que está pouco evidente, porém pode explicar muito as sucessões dos fatos. Ter lido essa parte dos drapeados da história provocou um deslocamento do meu ponto de partida, 
sobre o trabalho de Michel Foucault, retomando o conceito de prática discursiva. Os objetos não existem antes das práticas, destaca Veyne (2014); são os discursos praticados que constroem os objetos e, dessa forma, o texto escrito é mais uma materialidade de discursos sobre o objeto que se decide estudar e que passa a existir tal como é estudado e narrado, porque é estudado e narrado daquela forma. Outra pessoa que fale sobre o PL 867/15 estará também nesse processo construindo o objeto PL 867/15 a partir das implicações entre essa pessoa e o PL 867/15, e estou certa de que não teremos a mesma pesquisa.

No campo da linguagem, fica a reflexão de que não apenas analisamos enunciados e escrevemos suas regularidades linguísticas, por exemplo. Nós construímos nosso corpus, nós somos afetamos por ele e o afetamos, e, por fim, nós produzimos novos enunciados sobre esses enunciados com os quais trabalhamos. Nossas pesquisas passam também a compor a rede discursiva da qual os enunciados pesquisados fazem parte.

A leitura dessa parte do corpus, os projetos de lei, dava-se de uma forma em que posso voltar ao "Pistas do Método Cartográfico", mais especificamente à Pista 2, em que Katrupp (2009) fala sobre a atenção flutuante, concentrada e aberta. Como disse antes, há um processo cartográfico na feitura deste trabalho e gostaria de me ocupar de sua narrativa também para que faça sentido o caminho percorrido lá (2016 a 2018) e percorrido aqui. A leitura dessa Pista 2 se deu meses após a minha defesa (março de 2018); quando li esse capítulo, pude nomear, ou seja, dar existência, ao que eu tinha feito no meu trabalho com a potência do método escolhido. A leitura do corpus se dava com essa atenção flutuante e de modo a não buscar soluções, embora o tempo curto do mestrado coloque como uma tentação constante o desejo de encontrar logo resultados que sustentem a nossa hipótese inicial. Eu precisava encontrar uma entrada linguística, mas não lia e relia buscando uma especificamente. Até que vieram duas: a palavra 'ideologia', uma vez que ela aparecia bastante em trechos como "doutrinação política, moral, ideológica e religiosa”, fazendo-me pensar o que as vozes desses enunciados consideravam como 'ideologia', já que ela não era a 'moral', a 'política' e a 'religiosa', pela forma como está redigido o Projeto de Lei; e a segunda entrada foi a partir da expressão 'não', com a qual trabalhei por meio de conceitos da linguística pragmática para operacionalizar a análise. No entanto, antes de pensar nesse 'não' como a negação polêmica sugerida pela Pragmática $^{4}$, o que me veio foi a cenografia ${ }^{5}$ do texto, relembrando-me dos Dez Mandamentos da lei de Deus para judeus e cristãos.

Sobre a atenção do cartógrafo, Kastrup (2015, p. 33) diz:

Há dois pontos a serem examinados. O primeiro diz respeito à própria função da atenção, que não é de simples seleção de informações. Seu funcionamento não se identifica a atos de focalização para preparar a representação das formas do objeto, mas se faz através da detecção de signos e forças circulantes, ou seja, de pontas do processo em curso. A detecção e a apreensão de material, em princípio desconexo e fragmentado, de cenas e discursos, requerem uma concentração sem focalização, indicada por Gilles Deleuze no seu Abècèdaire através da ideia de uma atenção à espreita, cujo funcionamento vamos procurar elucidar. O segundo ponto é que a atenção, enquanto processo complexo, pode assumir diferentes funcionamentos: seletivo ou flutuante, focado ou desfocado, concentrado ou disperso, voluntário ou involuntário, em várias combinações como seleção voluntária, flutuação voluntária, concentração desfocada, focalização dispersa etc.

apesar de não estar mais no início da pesquisa. A leitura era daquelas despretensiosas, não direcionada à minha pesquisa, pois era uma proposta para o grupo que temos até hoje, que se encontra de quinze em quinze dias.

\footnotetext{
${ }^{4}$ Ducrot (1987) desenvolve conceitos no campo da polifonia, dentre eles o da negação polêmica. Para ele, de forma bem superficial porque este não é o foco do presente ensaio, a negação polêmica está presente em enunciados compostos pelo advérbio de negação "não" e que carregam, de modo pressuposto, enunciado cujo ponto de vista é afirmativo, logo, oposto. No caso da minha pesquisa, em "o professor não pode doutrinar", há um enunciado pressuposto de que “o professor pode doutrinar". Como fica difícil pensar em um ponto de vista que sustente a ideia de o professor poder doutrinar, pensamos em enunciados não do campo da permissão, mas no campo da possibilidade - o professor pode vir a doutrinar, então, proibamos essa atitude -, além de enunciados que sustentem a ideia de haver professores doutrinando. Ou seja, nos enunciados negativos que analisei, os pressupostos positivos não são opositivos em relação à negação, por isso eu os chamei de enunciados aliançados. São enunciados construídos de forma autoritária em muitos sentidos, pois em sua polêmica não se estabelece um outro ponto de vista, e sim o mesmo, o que faz aliança, não o que fala de modo contrário.

${ }^{5}$ A cenografia dos Dez Mandamentos ajudou a compreender o enunciador aliançado, mencionado na nota de rodapé anterior. Em "não matarás" não me parece ter um ponto de vista "matarás”, mas sim a possiblidade de assassinatos virem a acontecer ou de já estarem acontecendo. Quantoà cenografia, o conceito é de Dominique Maingueneau, que o desenvolve a partir da análise do gênero do discurso. Para o autor, todo gênero do discurso é travestido de uma cenografia que o legitima, o engendra, é a forma como esse gênero se apresenta, se materializa.
} 
Nesse tempo de construção do corpus, com muitas inquietações sobre as denúncias que via dos pais no site do Programa Escola Sem Partido, ia me questionando por que elas tinham relação com a desigualdade social, o racismo, as questões de gênero. Por que não querem que discutamos essas questões tão latentes do nosso país quando passaram anos nos questionando sobre o quanto a escola era distante da realidade? Talvez isso tivesse relação com o sentimento de apagamento das questões relacionadas a mim mesma, já que não falar de machismo era não falar sobre o que vivemos, nós mulheres, neste país tão violento; não falar das desigualdades sociais é não falar sobre o quanto é difícil a corrida para aqueles cuja renda per capita familiar é abaixo, bem abaixo, de mil reais, sabendo que eu cheguei aonde nem imaginava, mas muitos que cresceram comigo ficaram, inclusive os que tinham condições socioeconômicas piores que as minhas; não falar sobre racismo é simplesmente não fazer qualquer análise de Brasil em sala, uma vez que é impossível pensar na complexidade da nossa formação que se dá enraizada numa cultura escravocrata mantida até hoje nas relações sociais cotidianas, e é apagar mais ainda o que toca parte significativa da minha família, cuja árvore genealógica é difícil de se reconstruir e cujo embranquecimento foi sempre tão violento e forte; não falar sobre diversidade de gênero e de orientação sexual é perpetuar a violência existente num Brasil tão perigoso para homossexuais - que são nossos amigos, nossos alunos, nossos colegas de pesquisa e por aí vai. Ou seja, não poder falar sobre isso tudo em sala de aula era - e é - uma angústia que me moveu ao longo do trabalho, junto a uma raiva do corpus que fui construindo. O professor Bruno Deusdará falava isto muitas vezes: alguma relação temos de ter com o nosso corpus, a da Juliana é de ódio. É um afeto e, como tal, desloca. E, nesses deslocamentos todos, fui buscando outras leituras que não tinham relações tão imediatas com o meu trabalho, não eram do campo da teoria da Análise do Discurso, mas eu pensava: "em alguma hora pode ser que me seja útil". Assim, vieram-me os livros de Angela Davis, "Mulheres, Raça e Classe" (2016), e Judith Buttler, "Problemas de Gênero" (2003), dos quais eu lia um pedaço ali e outro aqui, sem saber muito se usaria ou não. Posteriormente, acabei utilizando trechos de "Mulheres, Raça e Classe", mais diretamente no capítulo 2, cujo título foi “A instabilidade da ordem vigente e a 'ideologia de gênero”". Ganhei do meu companheiro, também na época, o livro da Rebecca Solnit, "Os homens explicam tudo para mim", e algumas leituras breves, sem conseguir me ater somente ao livro por conta dos prazos de entrega da dissertação; pude também usar alguns trechos que abordavam, como no livro de Angela Davis, o lugar da mulher na nossa sociedade.

Essas reflexões me vieram não apenas, e inclusive, por eu ser mulher, mas porque Décio Rocha, meu orientador, sugeriu-me a leitura dos projetos de lei apensados ao PL 867/2015 que já mencionei - PL 7180/ 2014; PL 7181/ 2014; PL 1859/2015; PL 5487/2016; PL 6005/2016, além do PL 14111/2015, que havia, em 2015, despertado a minha atenção para o tema, quando discuti em sala de aula um artigo do O Globo, chamado Sombras, escrito por Fred Coelho, abordando a acusação de que professores assediavam ideologicamente alunos. Essa aula era com alunos de quinze anos, em uma escola da rede privada do Rio de Janeiro, e a ideia não era discutir se havia ou não assédio ideológico, porque eu realmente não me atentava ainda para tal disputa que já acontecia no país. A minha intenção era conversar com a turma sobre os estereótipos que criavam para os jovens, querendo ouvir o que aqueles adolescentes achavam sobre esses estereótipos e também como eles se viam. Foi uma aula que serviu como um dispositivo de mudanças, parecia que alguma coisa ali muito forte havia acontecido e que permitiu outros potentes encontros em sala de aula com aquela turma. Eles surpreendentemente mudaram o comportamento - ou eu talvez tenha mudado mais ainda. Enfim, voltando à construção do meu corpus, ao ler todos esses projetos de lei mencionados, fui caminhando numa pista que era a de que o problema da discussão de gênero poderia estar em discutir os direitos das mulheres. Os autores colocavam no mesmo saco a luta de classes estudada por Marx, a luta feminista, a chamada ideologia de gênero, e como os professores contribuíam para que tudo isso estivesse em sala, contaminando as crianças e os jovens, destruindo as famílias, afastando os alunos indefesos da verdade. Havia, então, para mim, uma rede, que chamei de rede discursiva, materializando-se em textos dispersos, num grande combate à destruição da propriedade privada - que aqui não é só a casa, as terras, os bancos, por exemplo, mas a família, sendo a mulher e os filhos a propriedade do homem.

Claro que todas essas pistas e esse caminho que fui traçando não foram possíveis só com a leitura dos projetos de lei e a análise linguística dos sintagmas que apresentavam a palavra "ideologia" ou a negação polêmica. Nesse trajeto, ouvi de um colega do grupo de pesquisa que existia uma página no Facebook chamada "Mães pelo Escola Sem Partido", a qual passei a seguir e acompanhar as postagens. Lá, bem como no site do Programa Escola Sem Partido, vi as “denúncias” de pais e outros responsáveis acerca da temível doutrinação feita por professores que têm a audiência cativa dos alunos. Nelas, o que pude perceber é que a doutrinação tinha a ver com temas voltados para a desigualdade social, o racismo e as questões de gênero. Não se pode falar de terras improdutivas; não se

Forum lingüístic., Florianópolis, v.17,n.4, p.5429-5441, out./dez.2020 
pode falar sobre violência contra a mulher ${ }^{6}$; não se pode falar sobre a existência de homossexuais; não se pode falar de negros e negras e do lugar sistemático onde a sociedade escravocrata que temos os coloca todos os dias. Fui, com isso, vendo que o que sustentava, como eu supunha no início da pesquisa, o Movimento Escola Sem Partido e os deputados favoráveis a ele, não era necessariamente uma moral religiosa, mas também, e fortemente, uma questão de mercado, já que a família também era representada como uma propriedade da estrutura patriarcal que temos. Não à toa temos a apropriação do lema "meu corpo, minhas regras" para "meu filho, minhas regras"!

Deslocar a mulher dessa estrutura é deslocar o patriarcado, como também é deslocar o mercado. Como diz Angela Davis, quando uma mulher negra na nossa sociedade se movimenta, toda a estrutura da sociedade se movimenta com ela (ALVES, 2017). E nessa proteção do mercado também podem estar as relações homoafetivas. Os gays e as lésbicas podem ter o "pink money", mas não filhos, ou seja, o capital humano. Nesse ponto, depois de muito tentar identificar alguma pista que pudesse ser um caminho para eu entender a intuição que tive sobre o deslocamento do patriarcado não ser só uma questão de moral religiosa, como também de mercado, lendo com o grupo de pesquisa o livro "Nascimento da Biopolítica" e conversando com Luiz Felipe, um orientando também do Décio, vi que ali poderia estar mais uma confirmação dessa rede toda que vinha cartografando.

No Capítulo 2 da dissertação, que foi o terceiro dentre os quatro que escrevi, abri uma seção cujo título foi "Não discutir gênero: ignorância ou interesse pelos privilégios?". Nela, há um trecho que retomo aqui:

A emancipação das mulheres e as possiblidades legais de uniões homoafetivas, sustentadas pelas discussões de igualdade de gênero, de respeito à diversidade sexual, de mudanças na cultura violenta do país em relação a mulheres e homossexuais, não são só questões que ferem a moral da família brasileira, são questões que mexem com o mercado, com a estabilidade do mercado e da ordem liberal. Não faria sentido para as concepções liberais a desigualdade de direitos, ou o não direito à liberdade para a pessoa ser o que ela quer ser; não faria sentido se o olhar for para o que dizem ser a finalidade do liberalismo nas sociedades. O olhar para o processo permitirá compreender que o capital muda quando a forma de se constituir família muda, e quando sobretudo essa nova forma de configuração familiar reduz o capital humano, a possibilidade de produzir novos empresários de si mesmos. (RETTICH, 2019, p. 63)

A noção de capital humano encontra-se no livro Nascimento da Biopolítica, de Foucault (2010, p. 289), que diz: "E quando uma sociedade colocar o problema do melhoramento do seu capital humano em geral, levantar-se-á certamente o problema do controle, da filtragem, do melhoramento do capital humano dos indivíduos em função das uniões e das procriações que se seguirão, que será feito ou, em todo caso, exigido".

Foucault (2010) vai apresentando como as relações econômicas foram sendo transformadas e como fomos nos tornando o que ele chama de empresários de si mesmos, desenvolvendo daí a ideia do capital humano - aqui destaco o quanto a explosão de coach parece ser a forma mais caricata dessa ideia de empresário de si mesmo. Contudo, preciso só "fechar" um pouco essa rede que havia comentado mais acima: mulheres decidindo sobre suas vidas, incluindo quando terão filhos ou se terão filhos ${ }^{7}$, e relações homoafetivas podem ser obstáculos para a produção de capital humano, desequilibrando o mercado. É interessante pensar em como os países da América Latina começam em tempos semelhantes o combate ao que se chama de ideologia de gênero, por exemplo,

\footnotetext{
${ }^{6}$ Miguel Nagib, junto ao Escola Sem Partido, começa a discutir a atribuição de nota zero nas redações do ENEM para quem ferisse os Direitos Humanos a partir do tema de 2015, "A persistência da violência contra a mulher", alegando que os candidatos devem ter direito à livre expressão. Em um evento organizado pelo colégio particular onde trabalho, em 2017, o próprio Nagib volta a esse assunto e fala abertamente que é direito de candidatos defenderem a violência contra a mulher. Nesse mesmo ano, foi movida uma ação civil pública pela Associação Escola Sem Partido a fim de suspenderem o critério já mencionado, e o Tribunal Regional Federal da $1^{\circ}$ Região dá o parecer favorável ao movimento, obrigando o INEP (Instituto Nacional de Estudos e Pesquisas Educacionais Anísio Teixeira), responsável pelo Exame Nacional do Ensino Médio, a suspender a anulação de redações que firam os Direitos Humanos.

${ }^{7}$ Vale apontar que essa liberdade ainda não existe de forma plena, embora algumas mulheres até acreditem nisso, por estarem no mercado de trabalho. Aqui destaco uma questão do movimento feminista e suas vertentes, dentre elas a que vê a entrada no mercado de trabalho como o ponto central da luta da mulher. É importante que não nos esqueçamos de que mulheres pobres estão no mercado de trabalho há muito tempo, geralmente em condições precárias, um cenário ainda visível hoje. Vale ainda dizer que muitas de nós, ainda bem alocadas nesse mercado, não temos a total liberdade de decisão sobre a maternidade, quando ainda ficamos inseguras quanto ao rendimento que teremos em uma gravidez, o que gera medo de perder o emprego ou de ter carga reduzida sendo horista, reduzindo a renda e prejudicando o sustento do bebê. E, como é meu caso, quando se decide conjugar sala de aula e pesquisa, o receio parece duplo, uma vez que dar conta de uma pesquisa e tentar se colocar na vida acadêmica, já com outro emprego e precisando dele, requer disponibilidade e disposição.
} 
com um apoio forte de setores religiosos, e sem a discussão do quanto somos, nestes países, capital humano para as grandes multinacionais.

Tecendo essa rede como cartógrafa, hoje a memória não me ajuda a narrar qual livro veio primeiro, qual passo primeiro dei, porém, sempre que falo um pouco sobre isso, o que me vem à mente é a imagem de um mapa, o mapa do Brasil, com o qual tive mais contato na minha formação escolar. Nele, costumo me ver saindo do Rio de Janeiro e indo em direção ao Norte, talvez Maranhão, depois volto ao Centro-Oeste, em seguida vou ao Sul, para voltar ao Rio. Nessas andanças, livros outros que já tinha lido reaparecem e contribuem para esse processo que estava vivendo. Lembrei-me agora, por exemplo, de "O segundo sexo", de Simone de Beauvoir, presente também de meu marido, quando éramos namorados. Isso para mim evidencia a implicação da cartógrafa no processo que decidi entrar ao fazer uma pesquisa de mestrado. O ponto de vista do observador como objetivo e sem relação alguma com o objeto que observa talvez seja uma das maiores falácias do fazer científico a fim de naturalizar o mundo que o pesquisador mesmo constrói ao narrar seus resultados. Acredito que seja importante dizer que o que afirmei agora não faz com que os resultados narrados sejam formas inexistentes, ao contrário, elas existem porque são ditas. Retomando Foucault, as práticas discursivas dão existência aos objetos, eles não precedem o dito.

Em um dos encontros, após a defesa da dissertação, conversava com o grupo sobre os lugares em que muitas vezes eu tinha ideias para percorrer, como pistas que me vinham. Nesse sentido, cabe uma outra implicação minha, sou católica, e às vezes na missa eu pensava em alguns pontos relacionados ao meu trabalho. Como católica, vivi também os conflitos de ver a Igreja trazendo a ideia da ideologia de gênero, corroborando o discurso do MESP, e, mais uma vez, deixando a mulher em segundo plano. Olhando agora para isso e aqui escrevendo, vejo o Capítulo 2 ("A instabilidade da ordem vigente e a ideologia de gênero"), já citado neste trabalho, como uma resposta a esses conflitos, que são forças que me atravessaram e potencializaram a vontade de concluir a dissertação, compreendendo-a como mais uma força que poderia disputar sentido neste campo em que se travou a discussão do Escola Sem Partido, com tantos outros problemas mais graves na escola para serem discutidos.

Nas andanças também, a partir de outro colega que fazia parte do grupo de pesquisa conheci o irmão da Fernanda Moura, autora da dissertação de mestrado "Escola Sem Partido: Relações entre Estado, Educação e Religião, e os impactos no ensino de história” e do já mencionado livro "Escola "sem" Partido - Esfinge que ameaça a educação e a sociedade brasileira", bastante importante para eu compreender como o MESP veio se delineando e ganhando espaço em forma de Projeto de Lei. A mesma importância dou ao trabalho desenvolvido pelos Professores contra o Escola Sem Partido, cujo líder é o professor Fernando Penna, que foi um dos membros da minha banca. A página do Facebook também me ajudou como fonte de pesquisa e de reflexão: produzimos algo em sala de aula que teve como resposta o MESP. Uma das etapas quase finais dessa minha cartografia foi a qualificação, onde pude ouvir dos professores Bruno Deusdará, Décio Rocha e Poliana Coeli não só apontamentos teóricos da Análise do Discurso, mas profundas falas sobre o nosso fazer em sala de aula. Um tom de batalha perdida, de derrota, de determinismo era o que se dava nas páginas apresentadas na qualificação. Lembro-me da Poliana Coeli me falando sobre isso e destacando a importância de eu rever a força da escola, do professor e da professora, a fim de que eu revisse também o trabalho que escrevia.

Hoje, mais forte do que antes, acredito que o trabalho mais árduo da cartografia é narrar o processo acompanhado. A escrita se deu, como agora, em meio à insegurança talvez inerente daqueles que sabem que as palavras constroem realidade. Essa noção foi também um vetor de força sobre mim, porque não se tratava apenas de um título acadêmico, tratava-se de um enunciado, mais um em disputa acerca da profissão que tardiamente escolhi e fui escolhida.

Ciente dessa responsabilidade, havia dois pontos fortes os quais chamo de vetores de força: não posso fazer interpretação de texto e preciso ser honesta com quem vai ler meu trabalho, narrando os passos que dei e as escolhas que fiz. Quanto ao primeiro, tem a ver com a disputa de sentidos acerca do que é a Análise do Discurso, por isso, e a partir da orientação dos três professores já mencionados, fui compondo o que chamei de rede discursiva, a partir de textos dispersos que materializavam discursos da chamada doutrinação em sala de aula. Aqui me vem a ideia de transversalidade proposta por Guattari, retomada no livro "Pistas do Método Cartográfico”, já na primeira pista, ao falar que a intervenção é sempre clínico-política. Nessa concepção, há duas coordenadas, vertical e horizontal, que vejo como vetores de forças, que vão definindo os indivíduos a partir desse par homogeneizador. Na página 29, há um desenho esclarecedor acompanhado do seguinte trecho: 
A operação de organização hegemônica do socius se faz pela oposição entre os eixos vertical e horizontal (coordenadas hegemônicas), realizando o sistema de rebatimento ou de superposição das variáveis maiores para a constituição de um metro-padrão que equaliza a realidade. Assim, por essa operação, há uma equivalência funcional entre o homem, adulto, heterossexual, branco, rico, variáveis maiores (dispostas no eixo vertical) que se rebatem umas sobre as outras, gerando uma existência ideal em oposição a qual se define mulher, criança, homossexual, negro, pobre, variáveis menores (eixo horizontal). Nesse sistema de rebatimento, é uma mesma operação que se realiza. Essa operação hierarquiza opondo as diferenças (homem x mulher, adulto x criança, branco $\mathrm{x}$ negro, heterossexual $\mathrm{x}$ homossexual, rico x pobre) e homogeneíza, seja criando um ideal de rebatimento das variáveis maiores entre si (homem-adulto-branco-heterossexual-rico), seja pela identificação e sujeição dos "diferentes" do ideal (mulher submetida ao homem, criança ao adulto, negro ao branco, homossexual ao heterossexual, pobre ao rico). (BARROS; PASSOS, 2015, p. 29)

A transversal é o eixo intermediário, onde opera a cartografia, e talvez eu possa dizer que o é porque é nele que há o rebatimento dos dois eixos, junto à implicação do cartógrafo, com uma dispersão de possibilidades a serem analisadas e talvez deixadas de lado se o método fosse linear, como o tradicional científico. Vou tentar traduzir essa ideia na forma como fui construindo e analisando o meu corpus: via, na materialidade linguística, a repetição da palavra ideologia, precisava entender que sentido em disputa estava nessa expressão. Embora o PL 867/2015 falasse de doutrinação religiosa e doutrinação ideológica, evidenciando uma diferença pressuposta entre ideologia e religião, por ser uma proposta da bancada da Bíblia, minha primeira hipótese foi a de que havia um discurso de uma moral religiosa por trás, sustentando esses textos que circulam sobre o ESP. Esse seria um dos eixos hegemônicos, produtor de subjetividade religiosa, em oposição ao outro eixo hegemônico, produtor de uma subjetividade não religiosa. A minha implicação como pesquisadora e também religiosa opera na transversalidade, trazendo-me a intuição de que poderia haver um local da dispersão no qual poderiam estar sendo produzidos outros devires, já que "[...] falar, portanto, de coeficientes de transversalização da clínica é intensificar/apostar mais, ou menos, nos devires que estão sempre presentes em diferentes graus de abertura e potências variadas de criação" (BARROS; PASSOS, 2015, p. 27). É nessa intuição que fui tentando construir a rede discursiva com textos dispersos, de locais diversos, além de ouvir os apontamentos dos colegas de grupo de pesquisa, para percorrer o caminho que começava a se abrir para mim e que era diferente do da hipótese inicial: não, não é só a moral religiosa que está em jogo nos textos do ESP, há um valor de mercado que o sustenta e o torna possível como textos circulantes dentro de comunidades discursivas. "Operar na transversalidade é considerar esse plano em que a realidade toda se comunica” (BARROS; PASSOS, 2015, p. 27). É nessa tentativa de fazer a realidade dispersa se comunicar que posso dizer que não fazemos interpretação de texto, mesmo que trabalhemos também com a pragmática, os postos, pressupostos e subentendidos; quando recorremos a outros textos e vamos cartografando uma rede, é uma forma de mostrarmos que o discurso o qual analisamos se materializa em diversos outros textos, e não é um achismo, uma vez que conseguimos mostrar, por meio das marcas linguísticas, o que estamos afirmando.

Sobre a rede que fui formando a partir da cartografia - que parece o método mais adequado para dar conta da dispersão na formação discursiva -, ao dizer que há um discurso machista ou racista que se materializa na expressão ideologia, diferenciada de política, moral ou religião quando aparecem os sintagmas doutrinação ideológica, só me foi possível fazer essa afirmativa quando recorri às denúncias dos pais no site Programa Escola Sem Partido ou na página do Facebook Mães pelo Escola Sem Partido, nas quais identifico que a chamada doutrinação ideológica é assim nomeada quando professores trabalham temáticas de gênero e de etnia em suas aulas. Lembro-me de atender os responsáveis de um aluno do primeiro ano do Ensino Médio, porque ele tinha escrito uma redação machista. Os pais não estavam denunciando a escola, ao contrário, foram chamados por ela, em função do texto do aluno que, além de fugir do tema proposto, era mais uma forma com a qual ele se expressava acerca da mulher na escola. O pai, muito agradecido pela atenção da instituição, entrou também dizendo: "as escolas hoje são muito voltadas para esquerda, é difícil, elas trabalham temáticas que não deveriam estar na escola, pois os alunos não têm maturidade. Os corredores estão cheios de cartazes de uma campanha contra o racismo, não era para o colégio trabalhar isso". Eu estava acompanhada por dois professores responsáveis por atendimentos com os pais, estando eu ali apenas como coordenadora da disciplina. A campanha antirracismo foi desenvolvida nas minhas aulas de redação com as turmas de segundo ano do Ensino Médio, após um mês de discussão acerca dos negros no país, buscando outras questões que não só a escravidão, a fim de que, ao menos no tema, a pluralidade fosse trabalhada nesse colégio no qual a maioria dos alunos e professores é branca, no qual os negros encontram-se geralmente em trabalhos como o de serviços gerais, e a justificativa quase sempre recai no passado, sem muitas reflexões sobre o quanto ainda hoje reproduzimos 
sistematicamente essa estrutura escravocrata. Porém, para aquele pai com quem tive que falar, esses temas não devem ser tratados na escola.

Se o primeiro vetor de força era a responsabilidade com a teoria que pretendi estudar, o segundo, como mencionei, era a honestidade com quem lesse a minha dissertação de mestrado, superando o desafio da narrativa. Na Pista 2, Kastrup (2015), diz que cartografar é acompanhar processos. Uma dificuldade inicial é se permitir ser uma cartógrafa, acompanhando processos sem antecipá-los ou nomeá-los antes de eles acontecerem; a segunda dificuldade é narrar esse processo, narrar como me coloquei como cartógrafa, quais foram as minhas escolhas e o porquê delas, sempre ciente de que a narrativa constrói realidade. Eu queria, como foi um desejo aqui, ser honesta ao falar sobre as minhas escolhas, mostrando-me como uma pesquisadora implicada no objeto e ele em mim, disposta a encontrar outras respostas diferentes das minhas hipóteses, aberta às possibilidades de ter de reformular a pesquisa, pegar um caminho de volta, se necessário, do Maranhão ao Rio de Janeiro, para traçar novos caminhos rumo ao Pará, por exemplo. E penso que, se eu comecei minha pesquisa achando que havia mais derrota do que vitória naquilo que acredito como educação, terminei-a compreendendo que é possível encontrar os equívocos dos agenciamentos, ir pelas brechas, buscando os vetores das transversais, e para novos deslocamentos, novos devires.

\section{CONSIDERAÇÕES FINAIS}

Chego ao fim deste trabalho no qual busquei fazer novamente um percurso vivido entre 2016 e 2018 para realizar minha pesquisa de mestrado. Sabendo que a cartografia ainda é um método pouco registrado como caminho de pesquisa por outras áreas que não a Psicologia, busquei aqui registrar o que temos feito com essa forma de produzir conhecimento. Como disse na Introdução, o caminho é contínuo e movente, o que me fez abrir somente três seções: Introdução, A cartografia como dispositivo e potência, e as Considerações Finais. Estas não tão finais assim, porque, cada vez em que eu voltar a falar da minha pesquisa de mestrado, outro processo movente se dará.

Ao finalizar estes escritos, revisitei novamente o início do meu mestrado, na segunda universidade pública que eu frequentava e construía, então um território de análise de produção potente de vida. Iniciei meu mestrado no mesmo ano de uma das maiores crises da Universidade do Estado do Rio de Janeiro, 2016. Uma crise que se arrastou sem nomearmos como crise ${ }^{8}$, uma vez que entrei na graduação em 2011 já sem papel higiênico, sem ar condicionado nas salas, sem salário em dia dos professores, sem bolsapermanência em dia para alunos cotistas, sem higiene nos banheiros, ou seja, elementos que nos possibilitariam efetivamente estudar, mas essas ausências não eram nomeadas como crise. Esse 2016, sem verba de custeio, fez a universidade paralisar. Não havia segurança no prédio, não havia serviço de limpeza, não havia bandejão, não havia condições de continuar as atividades sem as contas pagas, inclusive as das empresas que ofereciam os serviços com terceirizados, que foram demitidos em massa. Era um retrato de futuros possíveis cenários com os cortes da educação propostos pelo Ministério da Educação agora em 2019, porque a educação pública é atacada sistematicamente e o Escola Sem Partido é só mais uma forma de tentar legitimar esse ataque.

Voltando ao meu primeiro semestre de mestrado, sem aulas, tivemos encontros do grupo de pesquisa para de alguma forma vivermos o campo de forças da coletividade e as possibilidades de multiplicidade desse uno que era o grupo, subindo junto pelas escadas até $011^{\circ}$ andar porque o elevador estava sem manutenção e porque tínhamos de subir juntos por segurança. Dos encontros nasceram dois eventos chamados de "Linguística para quê?", nos quais falávamos das nossas pesquisas e, mais que isso, mostrávamos que a UERJ resiste e que ninguém pode definir seu fim quando as práticas demonstram a potência da existência dessa universidade. Ao final de todo o meu mestrado, tudo isso veio à tona e compôs as minhas 132 páginas de dissertação, fruto de vários encontros ao longo da minha vida, incluindo as duas graduações em universidade pública, em um momento do país em que me foi possível sair de Irajá, subúrbio do Rio de Janeiro, e chegar ao doutorado hoje - e a primeira da família, até onde sei, a chegar até aqui. Permitir que todas essas implicações estivessem presentes naquela pesquisa de março de 2016 a março de 2018, orientada por Décio Rocha, coorientada por Bruno Deusdará, Poliana Coeli e por todos os meus colegas do grupo de pesquisa, é uma força para mostrar que

\footnotetext{
${ }^{8}$ A aluna do Programa de Pós-Graduação do Instituto de Letras da UERJ Ariane Oliveira, em sua dissertação de mestrado, está colocando em disputa exatamente o conceito de crise da universidade, analisando notícias que relatam esse momento que citei.
} 
ciência se faz na prática cotidiana, nos encontros, nos processos. E é preciso que isso seja dito por nós que estamos na academia. Chego ao dia 26 de março de 2018, doze dias depois de executarem nossa vereadora negra Marielle Franco, para defender um trabalho que é uma resposta àqueles que querem nos silenciar e nos interromper nas salas de aula, lugar de semente. E só querem isso para aquilo que é potência, que é força, como ainda o é Marielle.

\section{REFERÊNCIAS}

ALVES, A. Angela Davis: “Quando a mulher negra se movimenta, toda a estrutura da sociedade se movimenta com ela”. El País. 27 ju. 2017. Disponível em: https://brasil.elpais.com/brasil/2017/07/27/politica/1501114503 610956.html. Acesso em: 30 jan. 2020.

AGAmBEN, G. O que é um dispositivo? Trad. Nilceia Valdati. Outra Travessia, Florianópolis, v. 5, p. 9-16, 2003-2016. Disponível em: https://periodicos.ufsc.br/index.php/Outra/issue/view/1201/showToc. Acesso em: 9 nov. 2020.

BARROS, L. P. E; KASTRUP, V. Cartografar é acompanhar processos. In: ESCÓSSIA, L.; KATRUP, V. PASSOS, E. (org.). Pistas do método cartográfico - pesquisa-intervenção e produção de subjetividade. Porto Alegre: Salina, 2015. p.52-75.

COELHO, F. Sombras. O Globo, 10 set. 2015. Disponível em: http://oglobo.globo.com/cultura/sombras-17229639. Acesso em: 30 jan. 2020.

DAVIS, A. Mulheres, raça e classe. Trad. Heci Regina Candiani. São Paulo: Boitempo, 2016.

DELEUZE, G.; GUATTARI, F. Mil platôs. 2. ed. São Paulo: Editora 34, 2011.

ESCÓSSIA, L; TEDESCO, S. O coletivo de forças como plano de experiência cartográfica. In: ESCÓSSIA, L.; KATRUP, V. PASSOS, E. (org.). Pistas do método cartográfico - pesquisa-intervenção e produção de subjetividade. Porto Alegre: Salina, 2015. p.92-108.

FOUCAUlT, M. Nascimento da biopolítica. Trad. Pedro Elói Duarte. Portugal: Edições 70, 2010.

FOUCAULT, M. Arqueologia do saber. Trad. Luiz Felipe Baeta Neves. 8. ed. Rio de Janeiro: Forense Universitária, 2012.

KATRUP, V. O funcionamento da atenção no trabalho do cartógrafo. In: ESCÓSSIA, L.; KATRUP, V. PASSOS, E. (org.). Pistas do método cartográfico - pesquisa-intervenção e produção de subjetividade. Porto Alegre: Salina, 2015. p. 33-51.

MIRANDA, L.; SOARES, L. Produzir subjetividade: o que significa? Estudos e pesquisas em Psicologia, Rio de Janeiro, ano 9, v. 2, p. 408-424, 2009.

MOURA, F. Escola Sem Partido: relações entre estado, educação e religião. 2016. 189 f. Dissertação (Mestrado Profissional em Ensino de História) - Instituto de História, Universidade Federal do Rio de Janeiro, Rio de Janeiro, 2016.

RETTICH, J. S. Do visor na porta das salas de aula à mordaça nos professores: uma análise discursiva das redes conservadoras do Escola Sem Partido - Projeto de Lei 867/2015. 2018.132 f. Dissertação (Mestrado) - Instituto de Letras, Universidade do Estado do Rio de Janeiro, Rio de Janeiro, 2018.

ROLNIK, S. Cartografia sentimental: transformações contemporâneas do desejo. Porto Alegre: Editora Sulina, 2016.

SOLNIT, R. Os homens explicam tudo para mim. Tradução de Isa Mara Lando. São Paulo: Cultrix, 2017. 
VEYNE, P. Como se escreve a história: Foucault revoluciona a história. Trad. Alda Baltar e Maria Auxiliadora Keipp. 4. ed. Brasília: Editora Universidade de Brasília, 2014.

() (1) $\circledast$

Recebido em 22/07/2019. Aceito em 15/01/2020. 